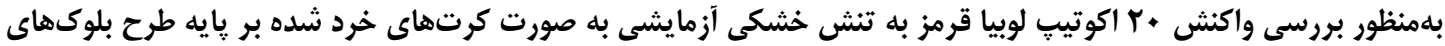

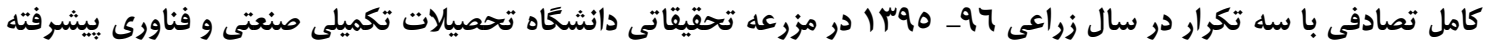

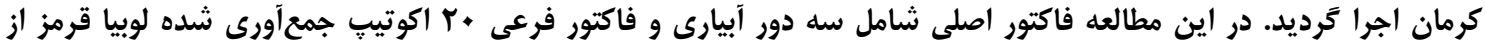

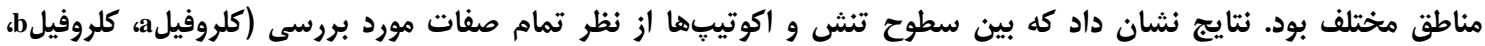

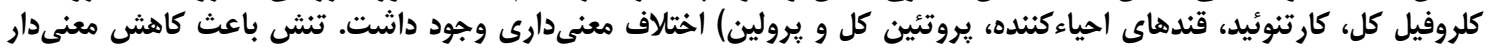

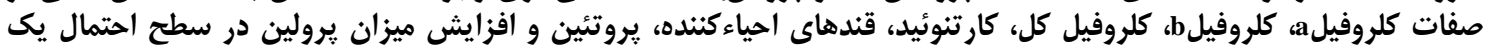

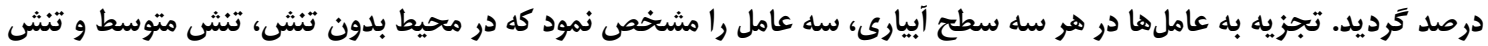

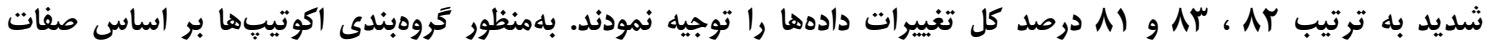

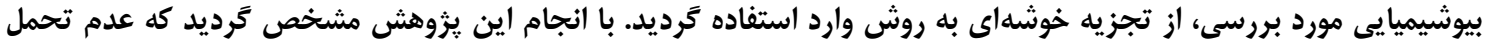

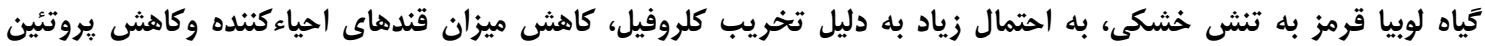

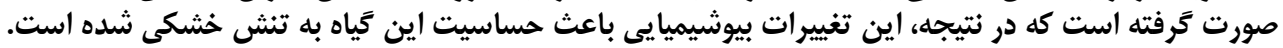

وازههاى كليدى: اكوتيب، رنكيزههاى فتوسنتزى، يرولين، تجزيه خوشهاى

كم آبى داراى اهميت مىباشد. گياهان براساس اينكه در خه ريه

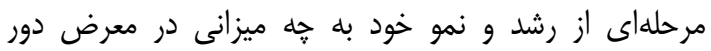

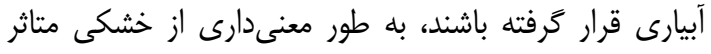

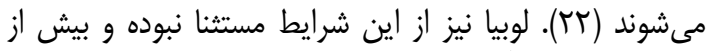

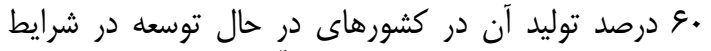
تنش خشكى انجام مى گيرد (TV)

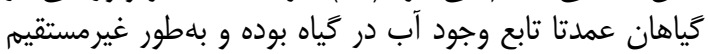

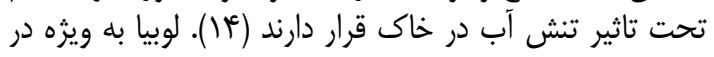

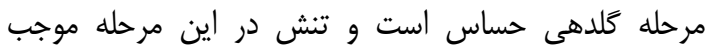

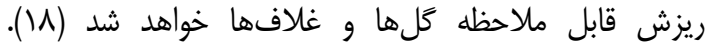

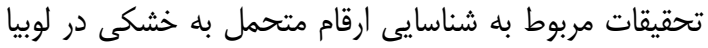

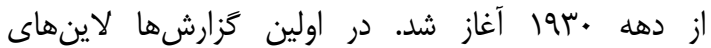

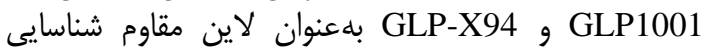
شدند. در مركز تحقيقات بين المللى محصولات گرمسيرى

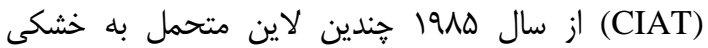

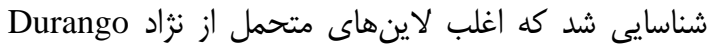

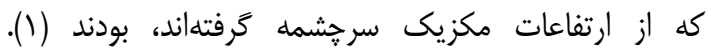

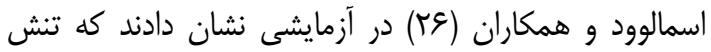

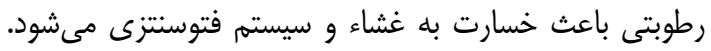

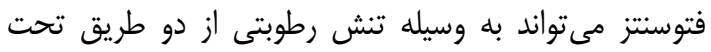

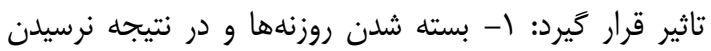

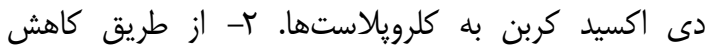

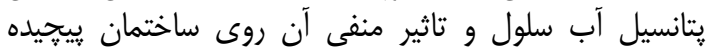

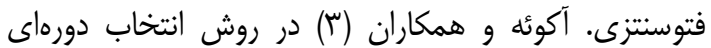

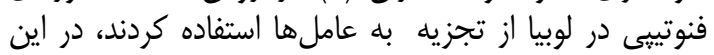
مقدمه ر از غلات، دومين منبع مهرم غذايى بشر حبوبات است.

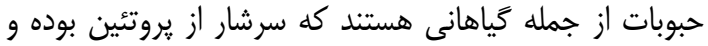

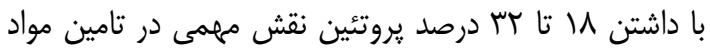

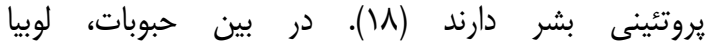
با توليد سالانه بيش از مبان ميليون (Phaseoluse Vulgaris)

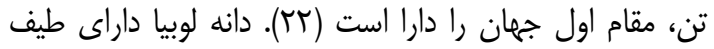

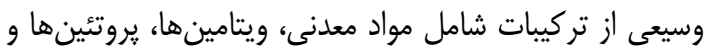

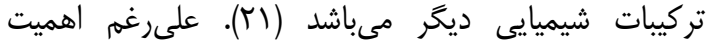

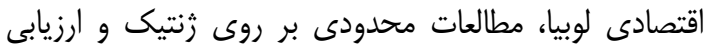

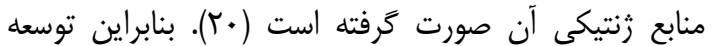

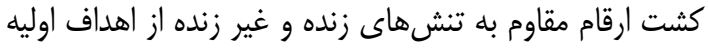

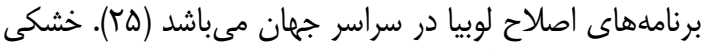

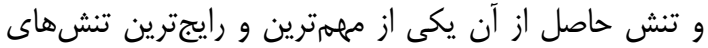

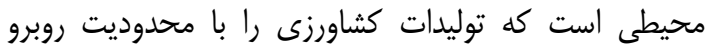

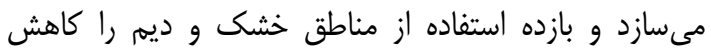

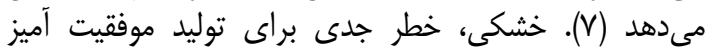

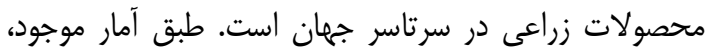

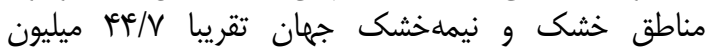

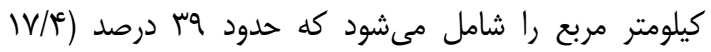

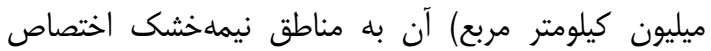

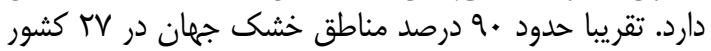

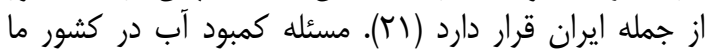

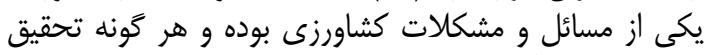

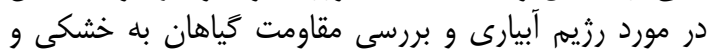




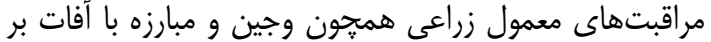

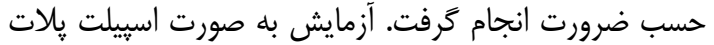

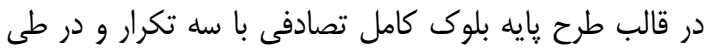

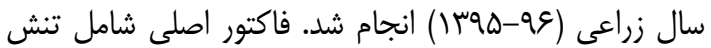

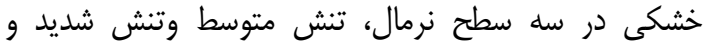

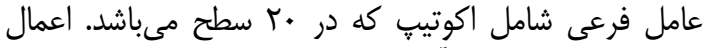

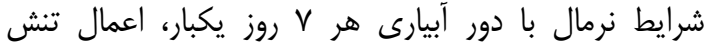

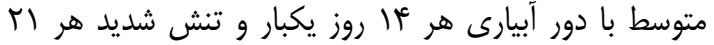

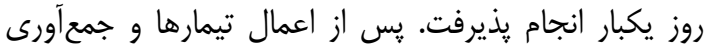

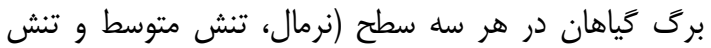

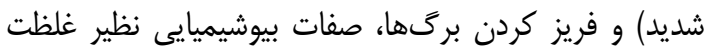

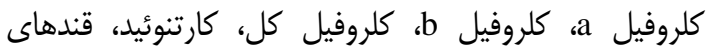

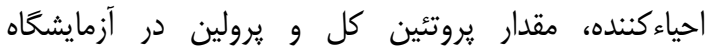

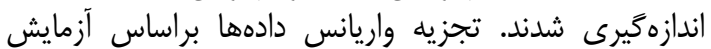

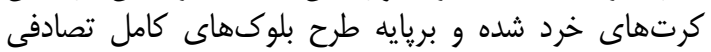

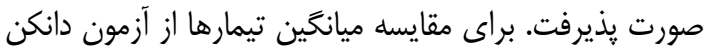

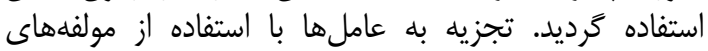

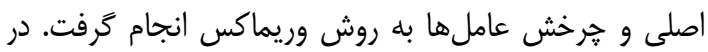

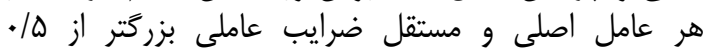

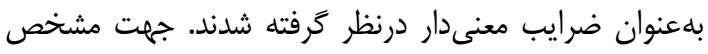

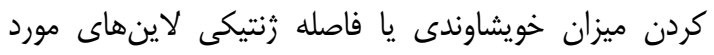

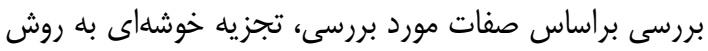
مقايسه حداقل واريانس وارد در هر سه شراس ترايط نرمال، تنش متوسط و تنش شديد انجام شدان

سنجش ميزان كلروفيل a، كلروفيل b، كلروفيل كل و كار تنوئيدها

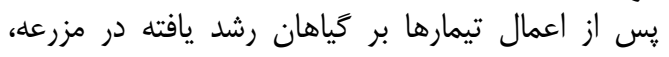

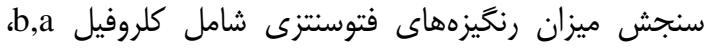

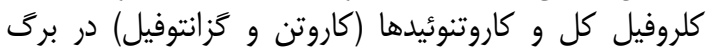

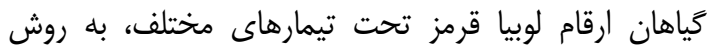

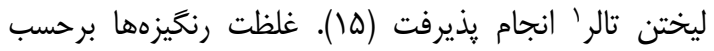

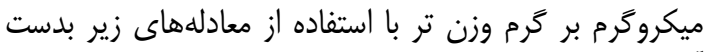

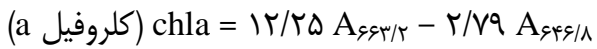

(كلروفيل) chlb = (كلروفيل)

Tchl = chla + chlb

$=\left(1+\cdots A_{p \gamma}-1 / \wedge\right.$ chla $-\Lambda \Delta / \cdot r$ chlb $) / 19 \Lambda$

(كار تنوئيد)

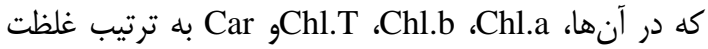

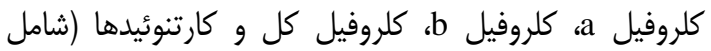

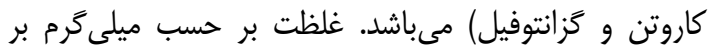

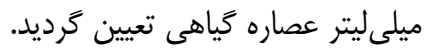
سنجش ميزان قندهاى احياكننده

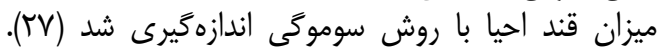

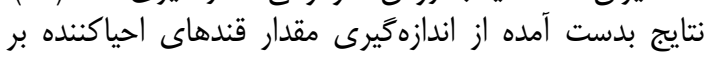

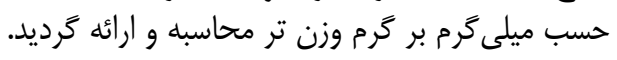

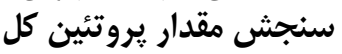
براى سنجش مقدار يروتئين، ابتدا يروتئينها از اندام

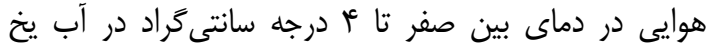

تجزيه ينج عامل اول •V درصد تنوع را توجيه كردند. تنش

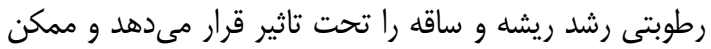

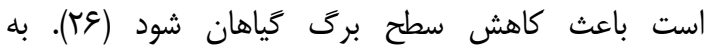

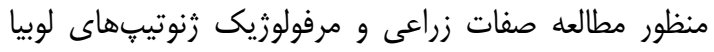

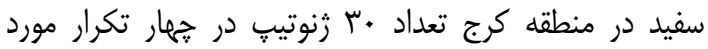

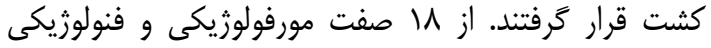

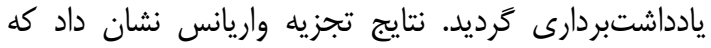

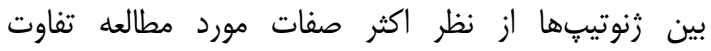

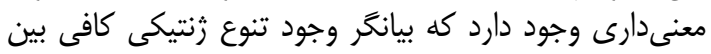

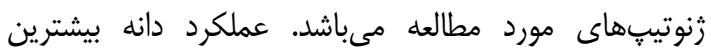

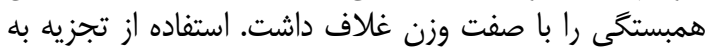

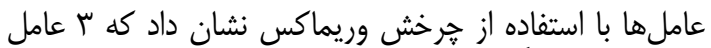

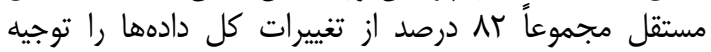

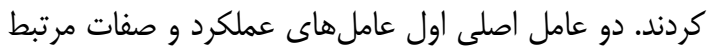

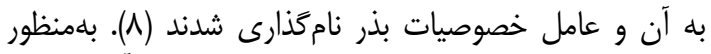

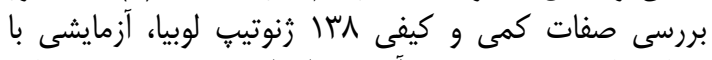

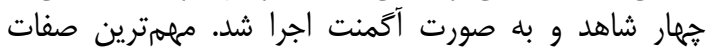

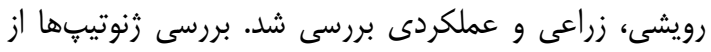

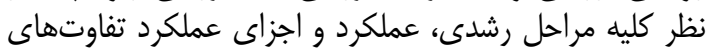

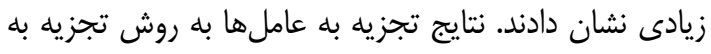

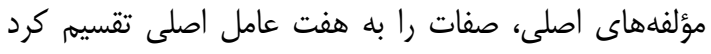

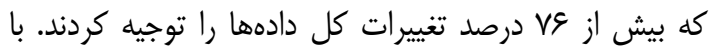

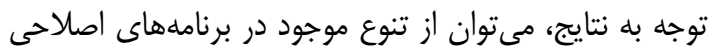

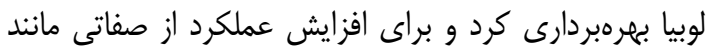

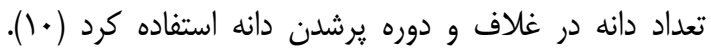

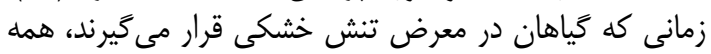

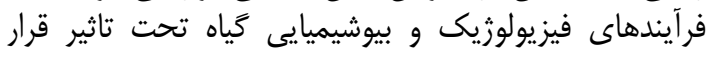

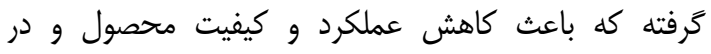

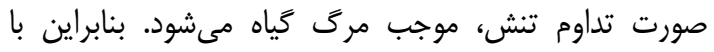

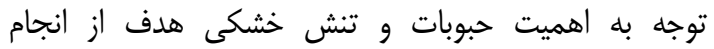

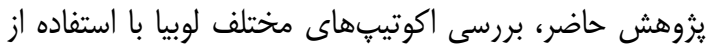

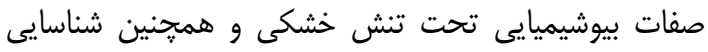
صفات مطلوب جهت كزينش اكوتيب بهتر مى تهاشد.

\section{مواد و روشها مزام}

تكمليات مزرعهاي در مزرعه تحقيقاتى دانشخاه تحصيلات

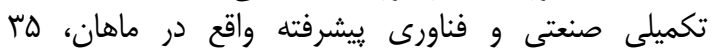

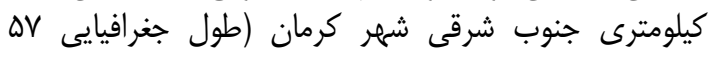

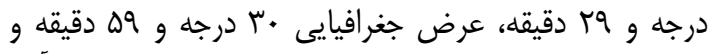

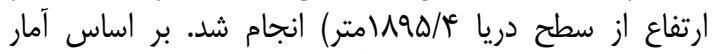

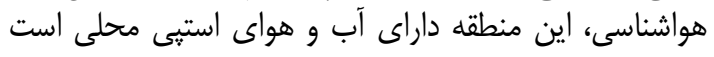

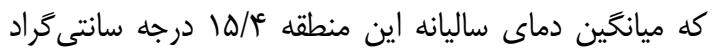

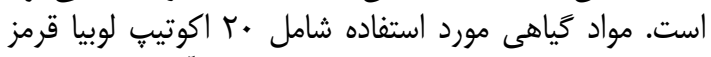

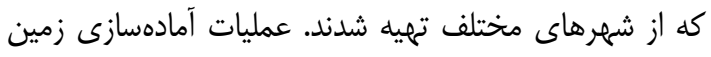

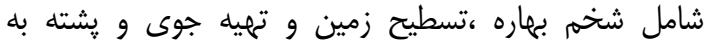

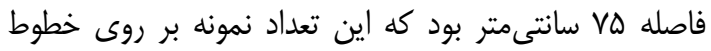

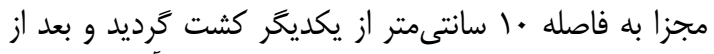

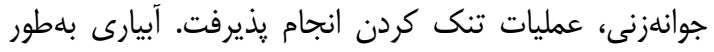
مرتب و تا زمان اعمال تنش براى كليه خطوط انجام يذيرفت. 
رشد بهترى نسبت به ساير اكوتيڤها از خود نشان دهند.

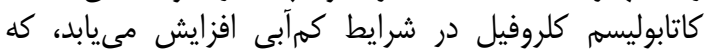

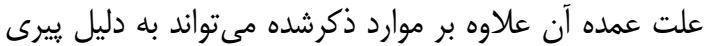

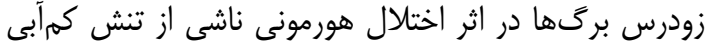

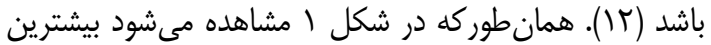

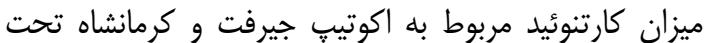

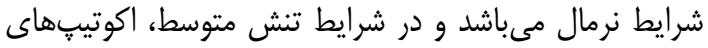

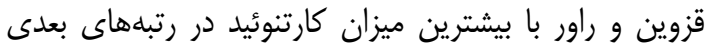

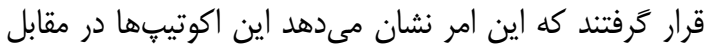

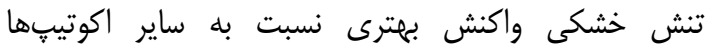

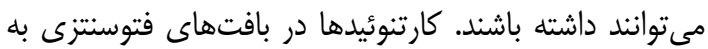

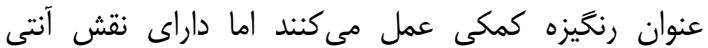

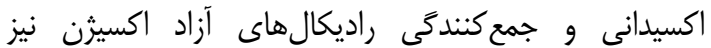

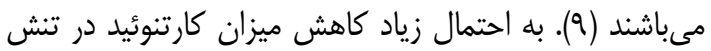

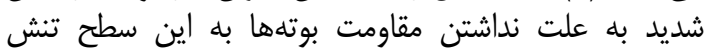

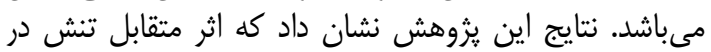

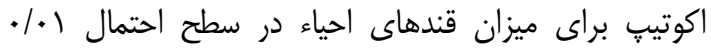

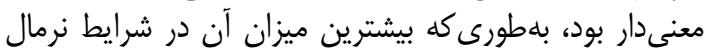

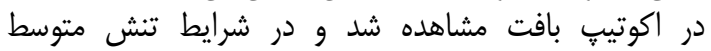

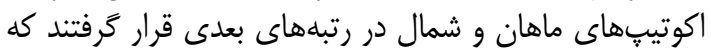

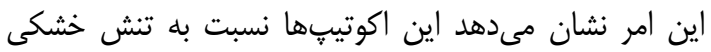

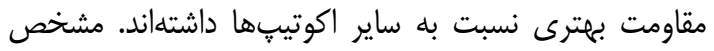

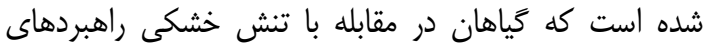

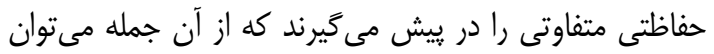

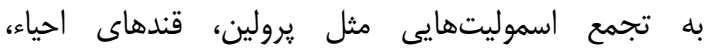

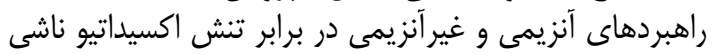

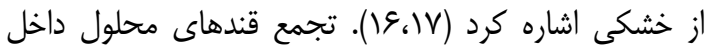

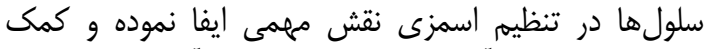

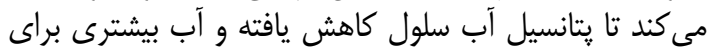

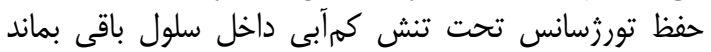

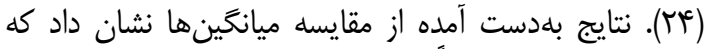

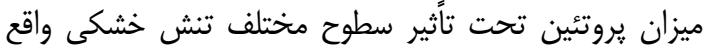

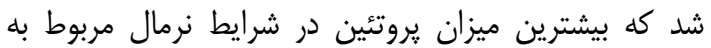

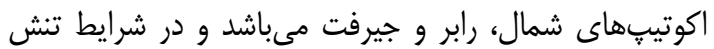

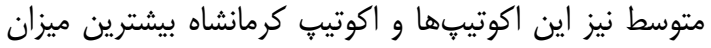

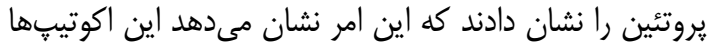

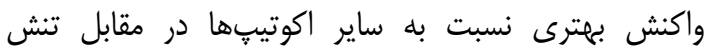

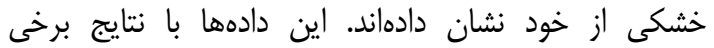

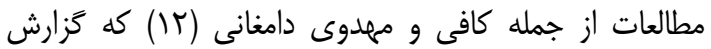

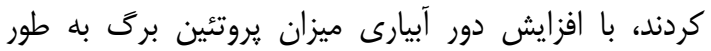

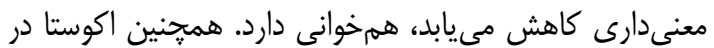

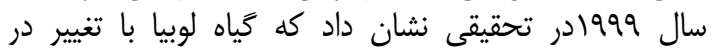

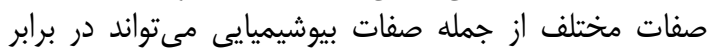

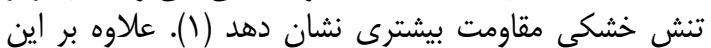

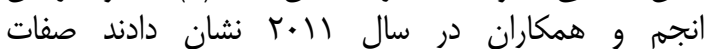

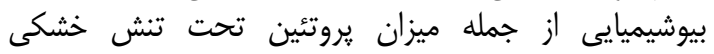
تغييرات معنىدارى نشان مى دهند (T) بئن
استخراج شدند. سنجش يروتئين كل نمونههاى مورد مطالعه

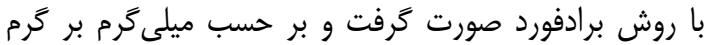

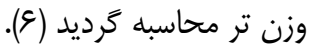
اندازهكيرى ميزان تيرولين

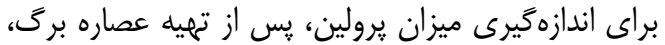
جذب يرولين در طول موج

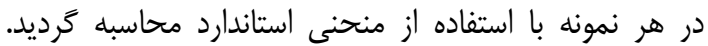

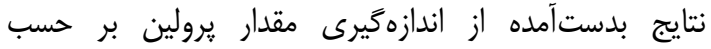

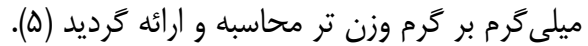

\section{نتايج و بحث

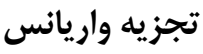

نتايج تجزيه واريانس براي كلي كليه صفات مورئ مورد مطالعه

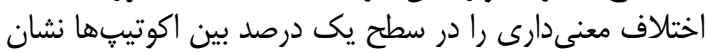

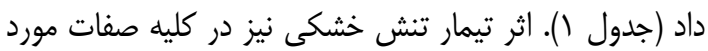

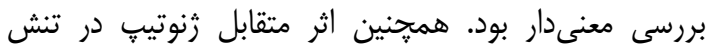

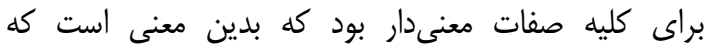

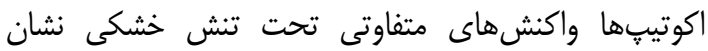

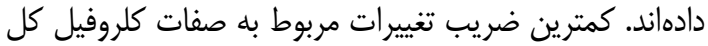

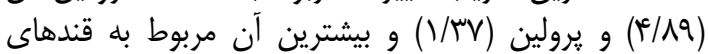

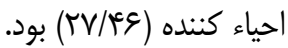

مقايسات ميانگين تيمار ها

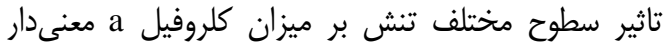

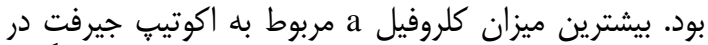

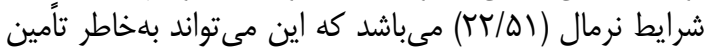

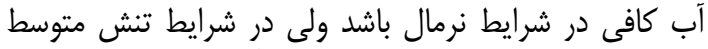

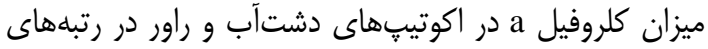

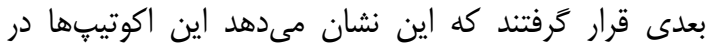

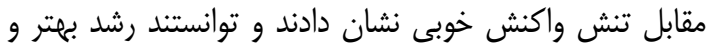

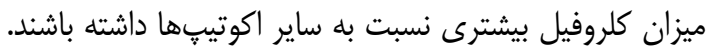

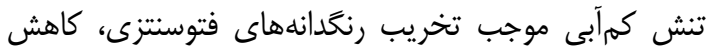

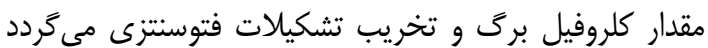

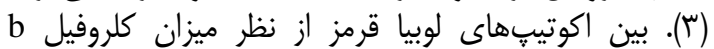

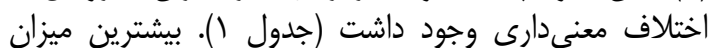

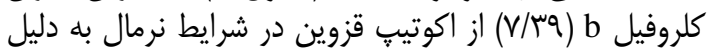

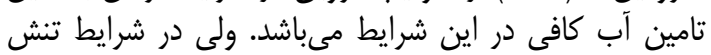

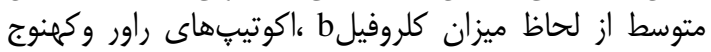

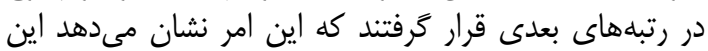

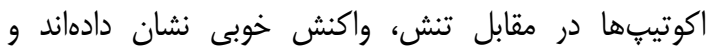

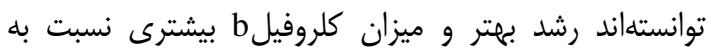

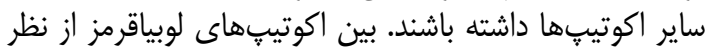

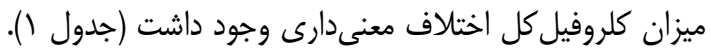

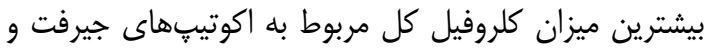

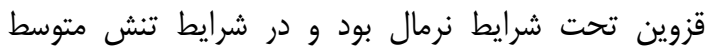

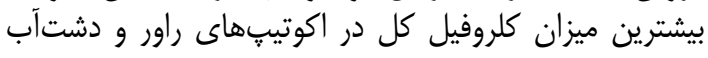

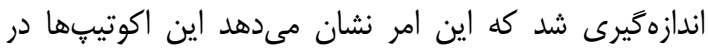
مقابل تنش خشكى واكنش خوبى نشان دادهاند و توانستهاند اند أند 
Table 1. Analysis of variance of studied traits in red bean ecotypes under drought stress

\begin{tabular}{|c|c|c|c|c|c|c|c|c|}
\hline $\begin{array}{l}\text { prolin ( يرولين } \\
\text { amino acid } \\
\text { (mg/gfw }\end{array}$ & $\begin{array}{c}\text { يروتئين كل } \\
\text { Total ) } \\
\text { proteins } \\
\text { (mg/gfw }\end{array}$ & $\begin{array}{c}\text { قندهاى احياكننده } \\
\text { Reducing sugar ) } \\
\text { (mg/gfw }\end{array}$ & $\begin{array}{c}\text { كارتنوئيد } \\
\text { caratenoied ) } \\
\text { (mg/gfw }\end{array}$ & $\begin{array}{c}\text { كلروفيل كل } \\
\text { chlt ) } \\
\text { (mg/gfw }\end{array}$ & $\begin{array}{c}\text { bلروفيل } \\
\text { (chlb mg/gfw) }\end{array}$ & $\begin{array}{c}\text { aلروفيل } \\
\text { (chla mg/gfw) }\end{array}$ & آزادى درجه & منابع تغييرات \\
\hline$f \Delta Q / I V^{* * a}$ & $\Lambda T F^{\varepsilon} \cdot / 8^{* * *}$ & $f \Delta F / M \Lambda^{* * *}$ & 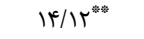 & 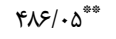 & $\Gamma q / r \Lambda^{* * *}$ & TrE/T & $r$ & a اثر خشكى a \\
\hline$\cdot / 1 \cdot \Delta$ & Tr/AV & $\Delta V / \Delta$ & I. & $.18 V G$ &.$/ \cdot M$ & $\cdot /$ ^ & f & خطا \\
\hline$\cdot / \cdot Y \Lambda$ & $\Delta F / F \Delta$ & $9 r / 19$ & $.1 \cdot+a$ & $\cdot / \Delta T$ & $\cdot / 4$ &.$/ 991$ & 114 & خطا \\
\hline $1 / r V^{e}$ & $\mid f / q 1 f$ & $t r / T E$ & $V / M l s$ & f/A98 & $11 / V I D$ & $9 / 109$ & & تغييرات (٪) \\
\hline
\end{tabular}
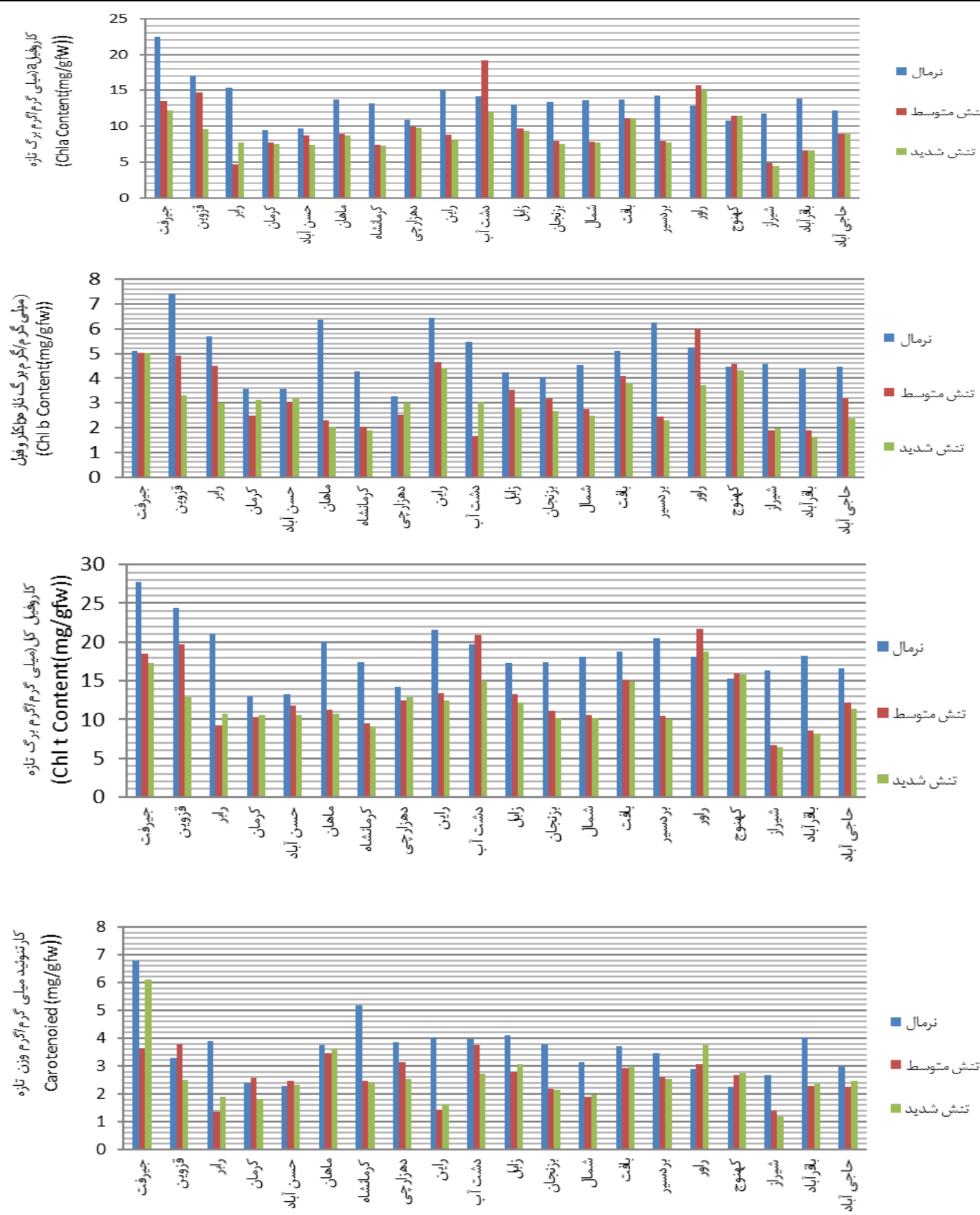

شكل (- مقايسه ميانخين اثرات متقابل تنش در اكوتيٍ براى كليه صفات مورد بررسى

Figure 1. Mean comparison of the interactions of stress in ecotypes for all studied traits 

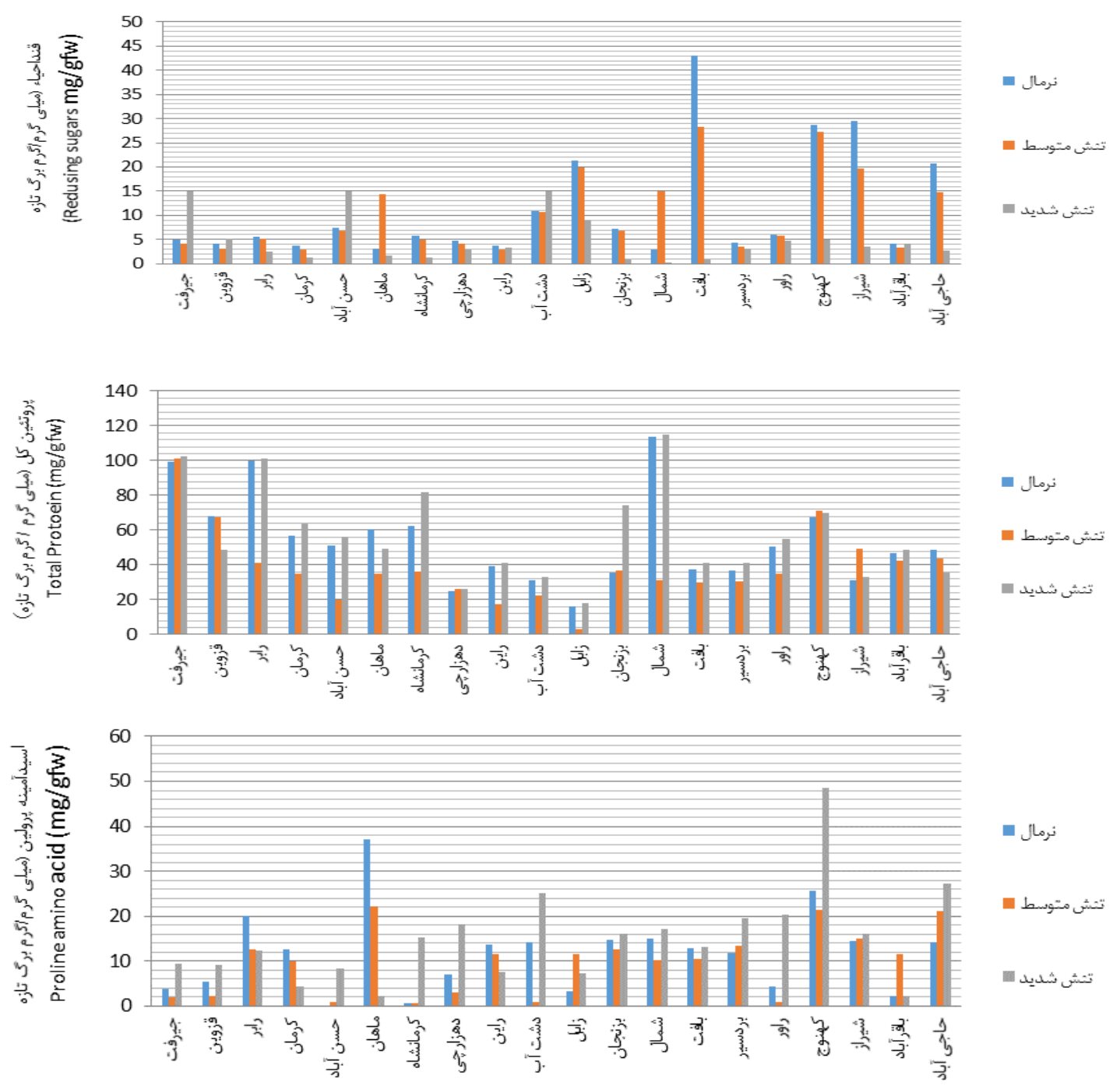

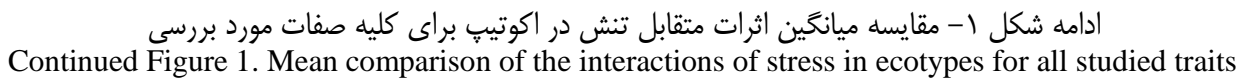

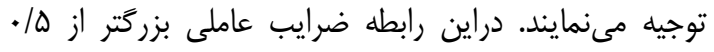

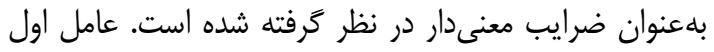

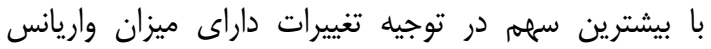

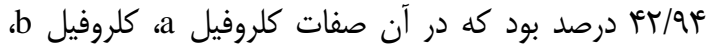

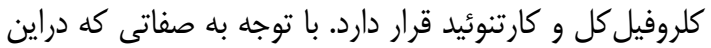

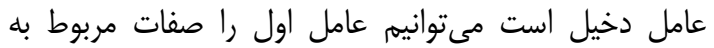

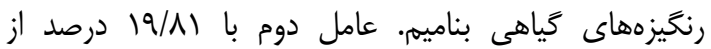

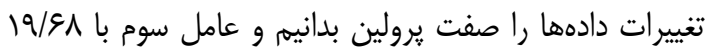

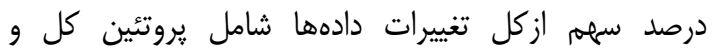

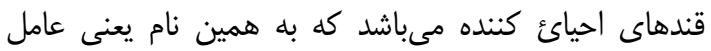

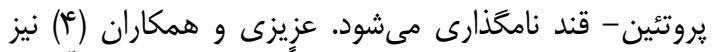

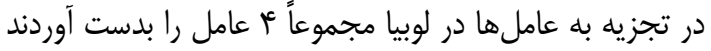

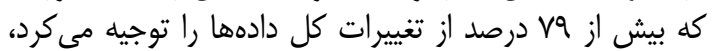

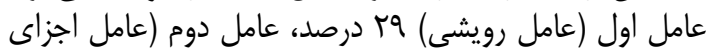

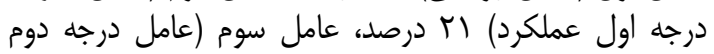

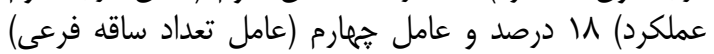

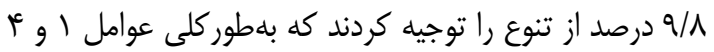

نتايج مربوط به ميزان يرولين نشان داد كه تاثير تنش خشكى با كذشت زمان سبب افزايش ميزان يرولين شدين نده است.

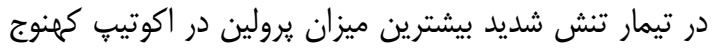

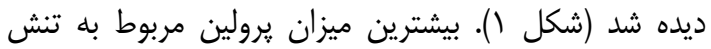

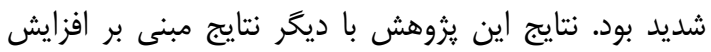

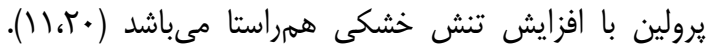

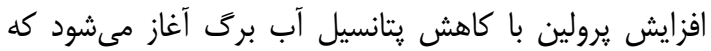

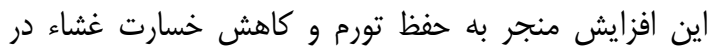

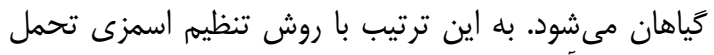

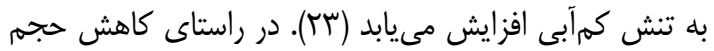

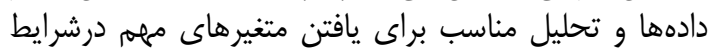

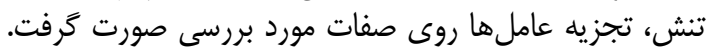

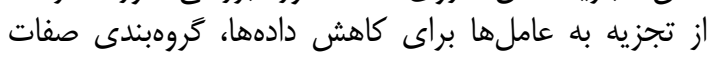

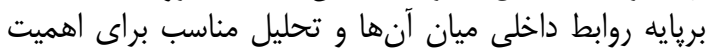

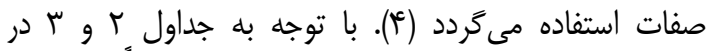

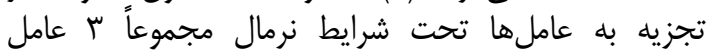

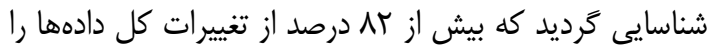


اول كلروفيل a، كلروفيل كل و كارتنوئيد را شامل مىشود كه

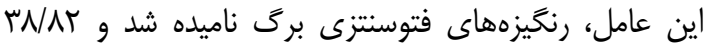

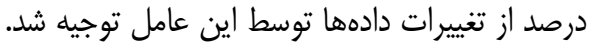

را عوامل رويشى و عوامل r و ب را عوامل مرتبط با عملكرد

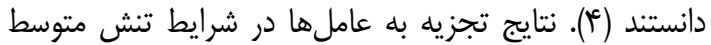

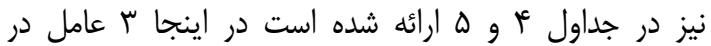

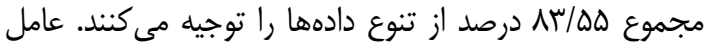

جدول r- مقادير ويثه و درصد واريانس هر عامل در تجزيه به عاملها تحت شرايط نرمال Table 2. Eigenvalues and percentage of variance of each factor in factor analysis under normal conditions

\begin{tabular}{|c|c|c|c|}
\hline درصدواريانس تجمعى & درصد واريانس & مقادير ويثه & عاملها \\
\hline Fr/qFi & Fr/qFi & $r / . .9$ & 1 \\
\hline GT/VQT & $19 / 11$. & $1 / \% \wedge V$ & r \\
\hline$\Lambda T / F T V$ & $19 / 9 \wedge \Delta$ & $1 / r V \Lambda$ & r \\
\hline
\end{tabular}

جدول r- ضرايب عاملى صفات مورد بررسى تحت شرايط نرمال Table 3. Factor coefficients of the studied traits under normal conditions

\begin{tabular}{|c|c|c|c|}
\hline \multicolumn{3}{|c|}{ ضرايب عاملى (يس از دوران وريماكس) } & \multirow[b]{2}{*}{ 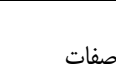 } \\
\hline عامل سوم & عامل دوم & عامل اول & \\
\hline$\cdot / 419$ & $\cdot / \cdot \mathrm{VV}$ & $\cdot / 9 \Delta 9$ & a كلروفيل a \\
\hline $.1 \cdot+\wedge$ & . Att & $\cdot / v \cdot 1$ & كلروفيل b \\
\hline.$/ \Lambda \wedge$ & .1 .91 &.$/ 941$ & كلروفيل كل \\
\hline . IFt & $-\cdot / 4+1$ & $\cdot \mid V 91$ & كارتنوئيد \\
\hline$-\cdot /$ Arq &.$/ 191$ & $-\cdot / \cdot \wedge \varepsilon$ & قندهاى احياء \\
\hline$\cdot / V 9 \Delta$ & Q & . /TE. & يروتئين كل \\
\hline $.1 . .9$ & $. / 9 .$. & $\cdot / \cdot \Delta \Delta$ & يرولين \\
\hline
\end{tabular}

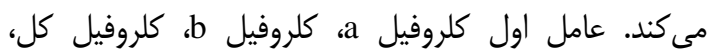

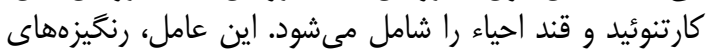

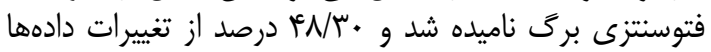

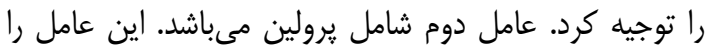

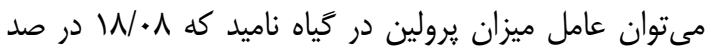
از تغييرات دادهها را توجيه مى كند.
عامل دوم شامل كلروفيل b و يروتئين كل مىباشد اين

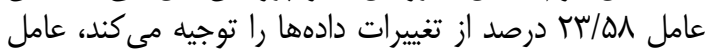

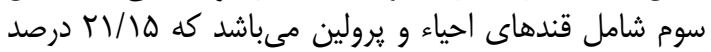

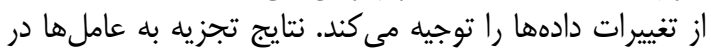

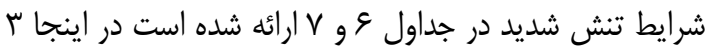

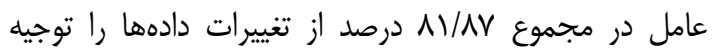

جدول fا- مقادير ويزه و درصد واريانس هرعامل در تجزيه به عاملها تحت شرايط تنش متوسط Table 4. Eigenvalues and percentage of variance of each factor in factor analysis under moderate conditions

\begin{tabular}{|c|c|c|c|}
\hline درصد واريانس تجمعى & درصد واريانس & مقادير ويزه & عاملها \\
\hline rN/Ar & $\Gamma / / \Lambda T$ & $T / V)$ & 1 \\
\hline$g \pi / 4$. & $r / \Delta \Lambda$ & $1 / 90$ & r \\
\hline$\Lambda \Gamma / \Delta \Delta$ & $r / / Q$ & $1 / 4 \wedge$ & r \\
\hline
\end{tabular}

Table 5. Factor coefficients of the studied traits under moderate conditions

$$
\text { ه- ضرايب عاملى صفات مورد بررسى تحت شرايط تنش متوسط }
$$

\begin{tabular}{|c|c|c|c|}
\hline \multicolumn{3}{|c|}{ ضرايب عاملى (يس از دوران وريماكس) } & \multirow{2}{*}{ صفات } \\
\hline 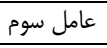 & عامل دوم & عامل اول & \\
\hline$-\cdot / \cdot \Lambda r$ & $\cdot / \pi / 4$ &.$/ 949$ & a كلروفيل \\
\hline$-\cdot / \cdot V \Delta$ & $\cdot / M$ &.$/ 199$ & كلروفيل b \\
\hline.$- / .94$ & . RET &.$|\Lambda \&|$ & كلروفيل كل \\
\hline$-\cdot / \cdot \Delta \Delta$ &.$/ . r q$ &.$/ 194$ & كارتنوئيد \\
\hline.$/ 94 \Lambda$ &.$/ . r q$ & $\cdot 11 \cdot 0$ & قندهاى احياء \\
\hline (1.94 &.$/$ V98 &.$/ N F$ & يروتئين كل \\
\hline . /V99 & -.1 .19 & $-\cdot / \uparrow \Delta \Lambda$ & يرولين \\
\hline
\end{tabular}

در نتايج ديده مىشود مهمترين عامل در بحث تجزيز مايه به ميه

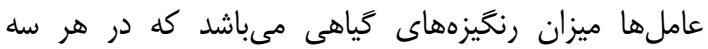

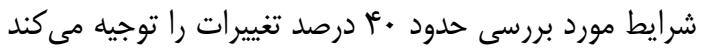

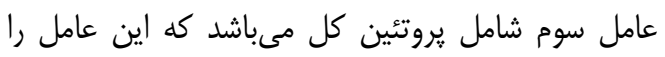

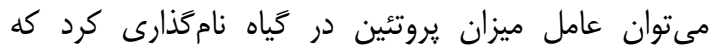

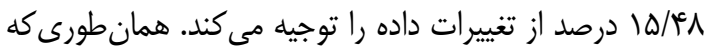


طورى كه در شكل r r مشاهده مى شود در حالت نرمال

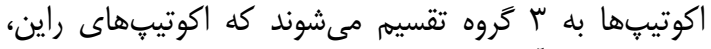

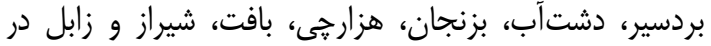

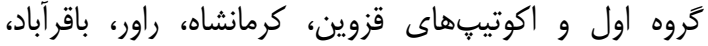

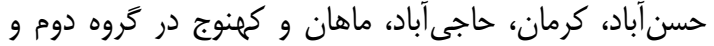

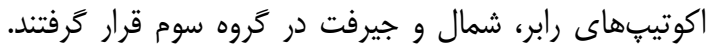

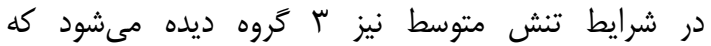

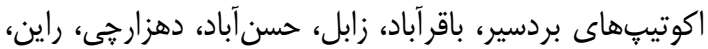

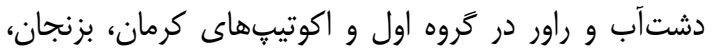

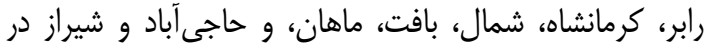

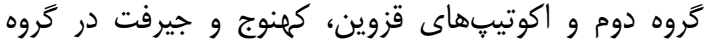

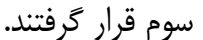

لذا بررسى رنخيزههاى فتوسنتزى براى مقايسه اكوتيبهاى

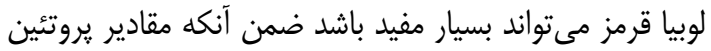

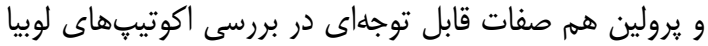

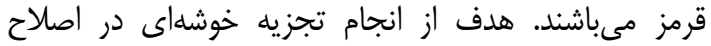

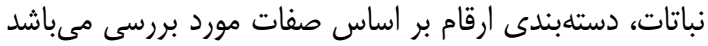

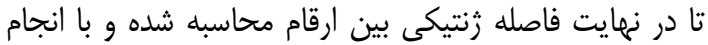

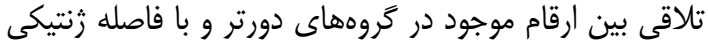

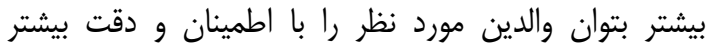

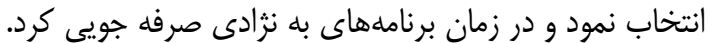

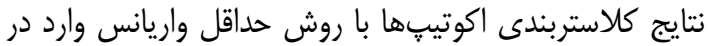

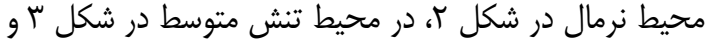

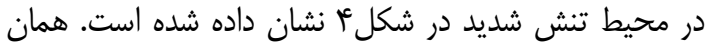

Table 6. Eigenvalues and percentage of variance of each factor in factor analysis under severe conditions

جدول צ- مقادير ويثه و درصد واريانس هرعامل در تجزيه به عاملها تحت شرايط تنش شديد

\begin{tabular}{|c|c|c|c|}
\hline درصدواريانس تجمعى & درصد واريانس & مقادير ويزه & عاملها \\
\hline$\hat{\kappa} \mathcal{N} / \boldsymbol{r}^{\prime}$ & $r N / \Gamma$. & $\mu / \mu \Lambda$ & 1 \\
\hline $98 / \% q$ & $\mathrm{~N} / \cdot 1$ & $1 / 48$ & r \\
\hline$\Lambda \backslash / A V$ & $\mid \omega / \mp \Lambda$ & $1 / \cdot 1$ & r \\
\hline
\end{tabular}

Table 7. Factor coefficients of the studied traits under severe conditions

جدول V- ضرايب عاملى صفات مورد بررسى تحت شرايط تنش شديد

\begin{tabular}{|c|c|c|c|}
\hline \multicolumn{3}{|c|}{ ضرايب عاملى (يس از دوران وريماكس) } & \multirow[b]{2}{*}{ صفات } \\
\hline 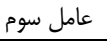 & 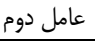 & عامل اول & \\
\hline$-. \cdot 1 .+\lambda$ &.$/ K E D$ & $\cdot / N \& V$ & كلروفيل a \\
\hline.$/ 199$ & $\cdot / T M$ & ./VAD & 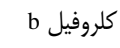 \\
\hline $.1 \cdot 11$ & $. / \% \Delta \mid$ &.$/ 911$ & كلروفيل كل \\
\hline.$/ 19$ &.$- / 199$ & . /AFV & كارتنوئيد \\
\hline$-\cdot / K M$ & Tht &.$/ 99 V$ & قندهاى احياء \\
\hline.$/ 9 V r$ &.$- / . r q$ &.$/ \cdot v$ & يروتئين كل \\
\hline$-\cdot / \cdot r r$ & $\cdot / 9 \cdot 4$ &.$/ N T \Delta$ & يرولين \\
\hline
\end{tabular}

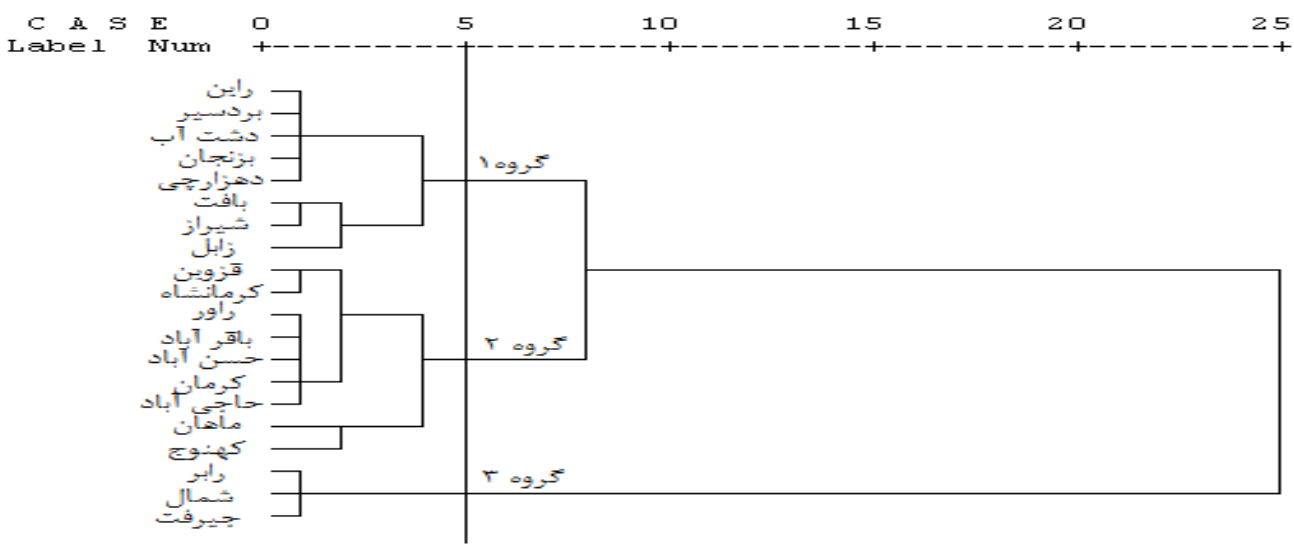

شكل r- تجزيه خوشهاى • ب اكوتيب لوبياقرمز تحت شرايط نرمال

Figure 2. Cluster analysis of 20 red bean ecotypes under normal conditions 


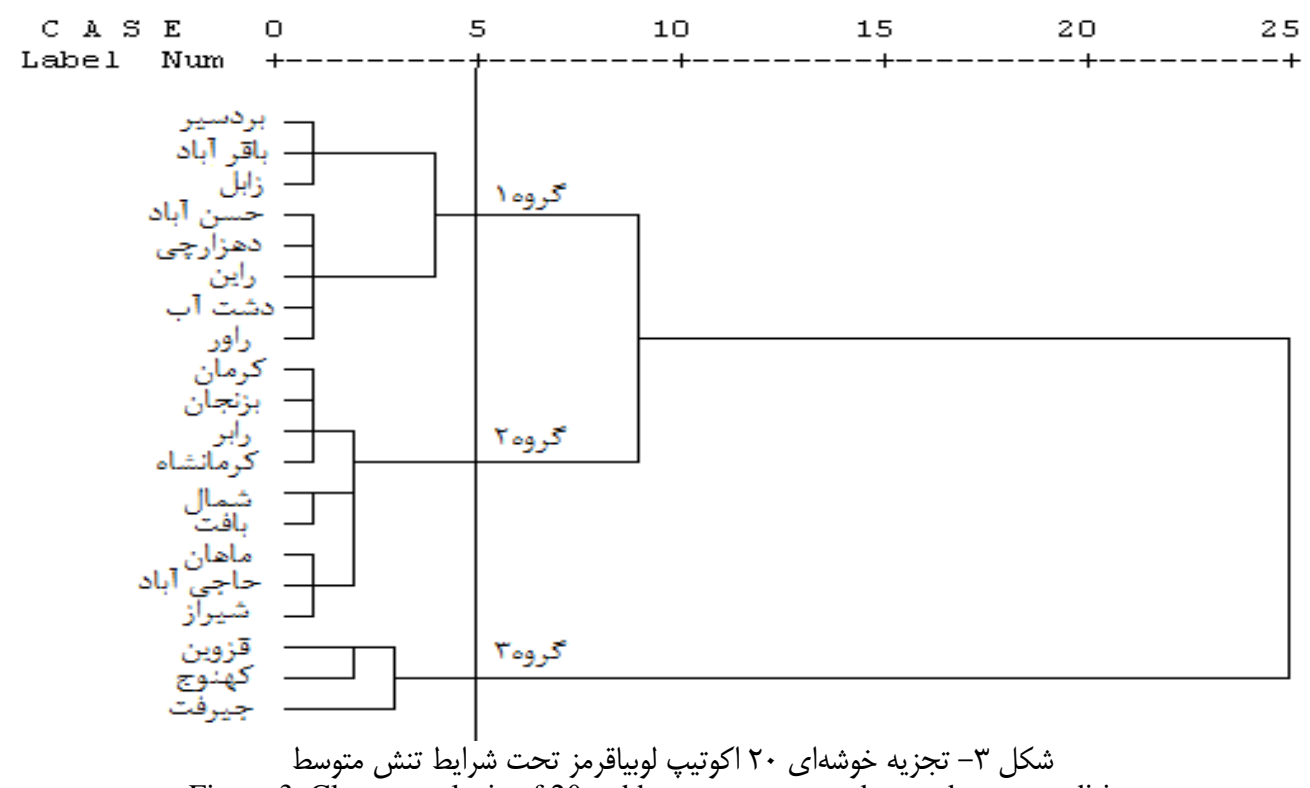

Figure 3. Cluster analysis of 20 red bean ecotypes under moderate conditions

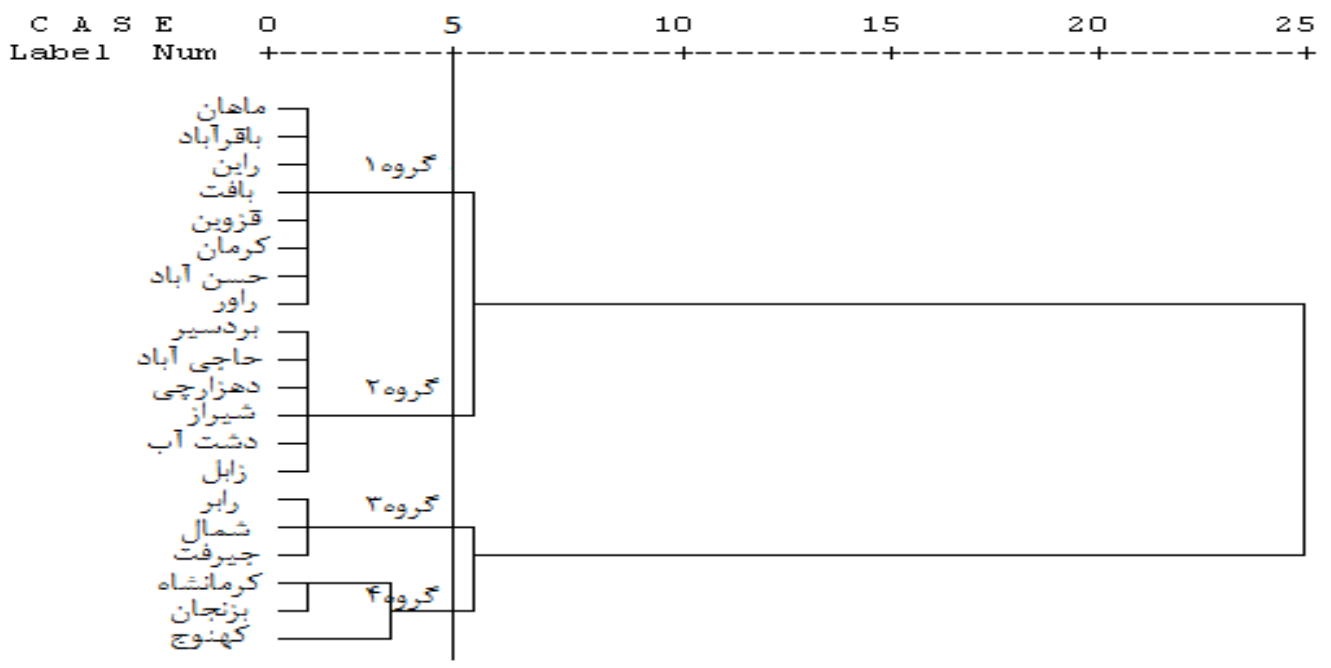

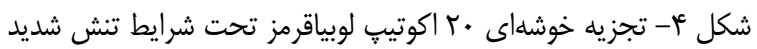

Figure 4. Cluster analysis of 20 red bean ecotypes under severe conditions

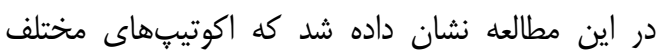

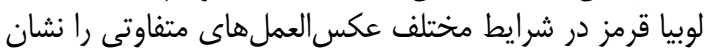

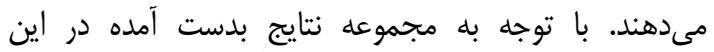

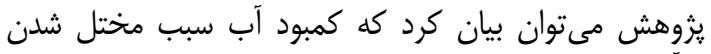

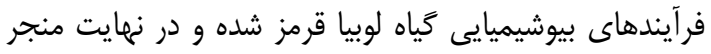

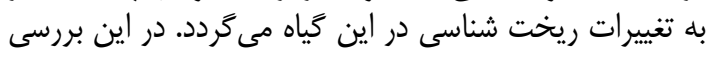

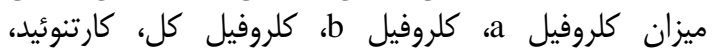

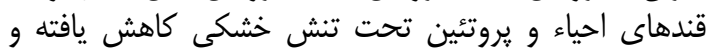

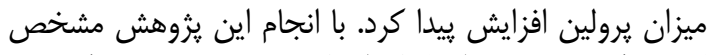

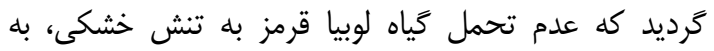

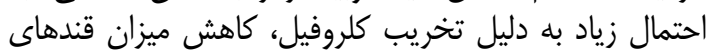

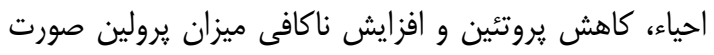

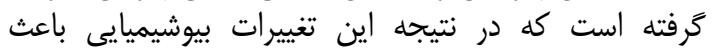
حساسيت اين گياه به تنش خشكى درئ شده است.
در شرايط تنش شديد اكوتيبها در ع كلاستر قرار گرفتند.

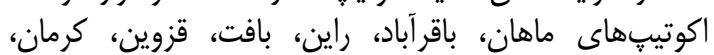

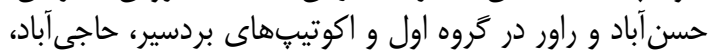

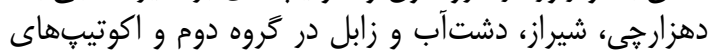

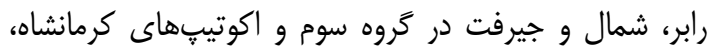

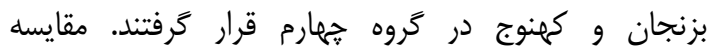

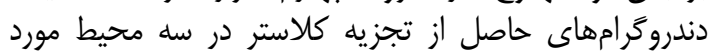

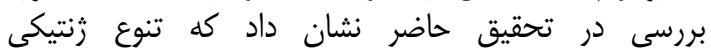

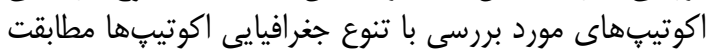

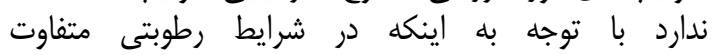

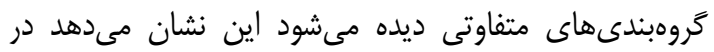

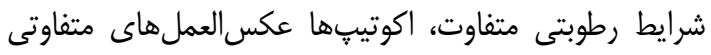

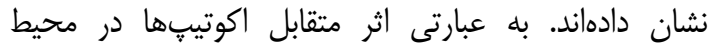

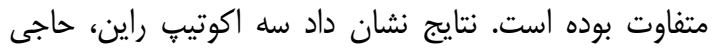

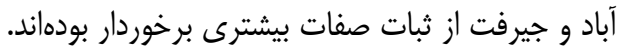


Acosta, J.A. 1999. Improving Resistance to drought in Common Bean, in Mexico. Agronomy Mesoamerican, 10: 83-90.

2. Anjum, S., X. Xie, L.Wang, M. Salem, C. Man and W. Lei. 2011. Morphological, physiological and biochemical responses of plants to drought stress. African journal of agricultural research, 6: 20262032.

3. Aquaah, G., M.W. Adams and J.D. Kelly. 1992. A factor analysis of plant variables associated with architecture and seed size in dry bean. Euphytica, 60: 171-177.

4. Azizi, F., A. Rezaei and M. Meibodi. 1997. Genetic and phenotypic variation and factor analysis for morphological traits in bean genotypes. Master's thesis, Faculty of Agriculture, University of Isfahan, (In Persian).

5. Bates, L.S., R.P. Waldron and I.D. Tear. 1973. Rapid determination of free proline for water studies. Plant Soil, 39: 205-208.

6. Bradford, M.M. 1976. A rapid and sensitive method for quantitation of microgram quantities of protein utilizing the principle of protein-dye binding. Analytical Biochemistry, 72: 248-254.

7. Eberhart, S.A. and W.A. Russel. 1996. Stability parameters for comparing varieties. Crop Science, 6: 36-40.

8. Ebrahimi, M., M.R. Bihamta, A. Hosseinzadeh, M. Golbashi and F. Khialparast. 2009. A study of agronomy and morphologic traits of white bean genotypes using multivariate analysis. Journal of Crop Breeding, 1: 1-13 (In Persian).

9. Egert, M. and M. Tevini. 2002. Influence of drought on some physiological parameters symptomatic for oxidative stress in leaves of chives (Allium schoenoprasum). Environ. Experimental Botany, 48: 43-49.

10. Ghanbari, A., H. Mozafari and H. Hosseinpour. 2017. Identification of effective traits on the yield in bean genotypes using multivariate statistical methods.Journal of Crop Breeding, 9: 53-62 (In Persian).

11. Johari-Pireivatlou, M. 2010. Effect of soil water stress on yield and proline content of four wheat lines. Afr. J. Biotech, 9: 36-40.

12. Kafi, M.A. and M. Mahdavi Damghani. 2003. Mechanisms of Environmental Stress Resistance in Plants. Ferdwsi University of Mashhad Press, Iran, 467 (In Persian).

13. Keshavarznia, R., E. Varznia, B. Mohammadi Nargesi and A. Abasi. 2013. The study of genetic variation of bean (Phaseolus vulgaris L.) based on morphological traits under normal and stress conditions. Iranian Journal of Field Crop Research, 44: 305-315 (In Persian).

14. Kramer, P.J. 1969. Plant and soil water relationships. Modem synthesis. Mc Grow-Hill Book co, New York, $84 \mathrm{pp}$.

15. Lichtenthder, H.K. 1987. Chlorophylls and carotenoids pigments of photosynthetic biomemberanes. Methods Enzymol, 148: 350-382.

16. Lotfi, N., K. Vahdati, B. Kholdebarin and R. Amiri. 2010a. soluble sugars and proline accumulation play a role as effective indices for drought tolerance screening in Persian walnut (Juglans regia L.) during germination. J. Fruits, 65: 97-112.

17. Lotfi, N., K. Vahdati, B. Kholdebarin, D. Hassani and R. Amiri. 2010b. Peroxidase, guaiacol peroxidase and ascorbate peroxidase activity accumulation in leaves and roots of walnut trees in response to drought stress. Acta Hort, 861: 309-316.

18. Majnon Hoseini, N. 2007. Common bean planting and production. $4^{\text {th }}$ edition, Tehran Jahad e Daneshgahi Press, 294 (In Persian).

19. Maralian, H., A. Ebadi, R.T. Didar and B. Haji-Eghrari. 2010. Influence of water deficit stress on wheat grain yield and proline accumulation rate. African journal of agricultural research, 5: 286-289.

20. Melotto, M., C.B. Monteiro-vitorello, A.G. Bruschi and L.E.A. Camargo. 2005. Comparative bioinformatics analysis of genes expressed in common bean (Phaseolus vulgaris L.) seedlings. Genome, 48: 562-570.

21. Mohammadi, D. 2013. Antioxidant activity and morphometric black bean genotypes in normal conditions and water stress, MSc dissertation, Faculty of Agriculture, Ilam University, Iran, $131 \mathrm{pp}$ (In Persian).

22. Parsa, M. and A. Baghri. 2007. Legumes. Mashhad Jahad-e Daneshgahi Press, 524 pp (In Persian).

23. Rahdari, P. and S.M. Hoseini. 2012. Drought Stress: A Review. Inter. Journal of agronomy and plant production, 3: 443-446.

24. Sato, F., H. Yoshioka, T. Fujiwara, H. Higashio, A. Uragami and S. Tokuda. 2004. Physiologycal responses of cabbage plug seedlings to water stress during low-temprature storage in darkness. Horticultural Science, 101:349-357.

25. Sepahvand, N.A. 2004. Research and production program of irrigated pulses and the challenges, the First National Grain Conference, Ferdosi University, 193-195 (In Persian).

26. Smallwood, M.F., C.M. Calvert and D.J. Bowles. 1999. Plant responses to environmental stress. BIOS Scientific Pub, Oxford, 348 pp.

27. Somogy, M. 1952. Note on sugar determitation. Journal of Biochemistry, 195: 19-29. 


\title{
Evaluation of Some Biochemical Characteristics of Some Red Bean Ecotypes under Drought Stress Conditions
}

\section{Amin Baghizadeh ${ }^{1}$, Somayeh Mohammadinejad ${ }^{2}$ and Mehdi Rahimi ${ }^{3}$}

\footnotetext{
1- Associate Professor Department of Biotechnology, Institute of Science and High Technology and Environmental Sciences, Graduate University of Advanced Technology, Kerman, Iran, (Corresponding author: amin_4156@yahoo.com)

2- M.Sc. of Plant Breeding, Faculty of Sciences and Modern Technologies, Graduate University of Advanced Technology, Kerman, Iran

3- Assistant Professor Department of Biotechnology, Institute of Science and High Technology and Environmental Sciences, Graduate University of Advanced Technology, Kerman, Iran Received: August 4, $2017 \quad$ Accepted: January 27, 2018
}

\begin{abstract}
For evaluation of the reaction of twenty red beans ecotypes to drought stress, an experiment was conducted in split plot as Randomized Complete Block Design with 3 replications in 20162017 at research field of Graduate University of Advanced Technology, Kerman, Iran. In this study, the main plots were three irrigation levels and sub-plot were twenty red beans ecotypes which they are sub-population from different regions of Iran. The results showed significant difference between stress levels and between ecotypes for all studied traits (chla, chlb, chlt, carotenoied, Redusing sugars, total porotein and prolin amino acid). Stress caused to significantly decrease in level 0.01 of chla, chlb, chlt, carotenoied, Redusing sugars, total porotein and caused to significantly increase in level 0.01 of prolin amino acid. There were 3 factors that explained 82 percent in non stress condition and 83 percent of total variations in moderate stress condition and 81 percent of total variations in severe stress condition. Cluster analysis (Ward) was used to categorize ecotypes based on biochemical traits. This study showed that the in tolerance of red bean plant to drought stress was most likely due to chlorophyll degradation, reduction in sugars and protein reduction. As a result, these biochemical changes have made the plant susceptible to drought stress.
\end{abstract}

Keywords: Cluster analysis, Ecotype, Photosynthetic pigments, Proline 